\title{
Investigation of the Mathematical Thinking Processes of Students in Mathematics Education Supported with Graph Theory
}

\author{
Sevinç Mert Uyangör \\ Faculty of Necatibey Education, Balıkesir University, Turkey
}

Copyright $\mathrm{O} 2019$ by authors, all rights reserved. Authors agree that this article remains permanently open access under the terms of the Creative Commons Attribution License 4.0 International License

\begin{abstract}
In the most general sense, mathematical thinking can be defined as using mathematical techniques, concepts, and methods, directly or indirectly, in the problem-solving process. In this study, efforts were made to include the Graph Theory of mathematics, which is found abundantly in physics, chemistry, computer networks, economics, administrative science, data communication, transportation planning, engineering, and similar areas of daily life, into the mathematics instruction process. Because suitable problems are selected in graph theory, the mathematical thinking skills of the students can be developed. A fundamental, qualitative research approach was adopted in this study, in which the mathematical thinking processes of 12th-grade students were examined. Two girls and two boys with average and high mathematics success who were in the 12th grade of a public school in Balıkesir in the 2018-2019 Academic School year constituted the working group of the research. The data in the study were collected with the two worksheets the researchers prepared, the clinical interviews held during the application, and through unstructured observations. The results obtained by analyzing the data in the process of mathematics teaching, in which graph theory included are: When students solved the problems they faced and when they ascend top steps of mathematical thinking, they showed a better performance when compared to the other studies. Because, in the steps of privatization, generalization and assumption, only 1 of the total 8 responses given by the students is empty. At the stage of proof which is the final stage of mathematical thinking, the students have achieved a success rate of $75 \%$ despite they did not have a lesson about making proofs. This situation was interpreted as the visual model of problems selected from graph theory and attracting the attention of the questions as stated by the students. The results of this study show that, in the process of mathematics teaching, especially if teachers provide enough diversity students by using different fields of
\end{abstract}

mathematics, they can increase the performances of students in mathematical thinking stages.

Keywords Mathematics Education, Mathematical Thinking, Graph Theory

\section{Introduction}

In our age, to say "education, instruction" means to know how to think and research and how to teach these to younger generations [1]. To give students superior thinking skills like scientific, creative, democratic, multidimensional, mathematical, and critical thinking must be the most important duty of all educators. Individuals who have the desired characteristics can be cultivated with the implementation of educational programs based on these skills [2]. When general goals of the Mathematics Curriculum that were renewed in our country in recent years $(2013,2017,2018)$ are examined in this context, it is vocalized that there is a greater need than normal for individuals who value mathematics, whose strength of mathematical-thinking has developed, and who can use mathematics in modelling and problem-solving in the world of today, which encounters new problems that previous generations didn't as a result of developments in technology. Thus, instruction programs aim to develop the problem-solving skills of students by looking at problems from different perspectives, to earn mathematical thinking and application skills, to accurately, effectively, and beneficially use mathematics, to develop a perspective on whether a problem they encounter in life is a problem for them and reach a certain level of knowledge, and more [3].

When reviewing the literature, it can be said that, in the eyes of mathematicians, mathematics is a single method of thinking that brings individuals to truth and definitive knowledge [4]. In order for thinking to arise, a problem 
must be specified. An individual tries to solve the problem by establishing a relationship between concepts, and thinking begins at this stage [5]. Mathematics doesn't just reside with teaching numbers and operations but supports people by providing significant achievements like thinking, establishing bonds between incidents, reasoning, estimating, and solving problems in the battle of life that grows more chaotic with each passing day [6].

The concept of mathematical thinking encountered in the process of mathematics instruction, according to Schoenfeld [7], means to look with a mathematician's eye at the world with the development of a mathematical perspective. Henderson [8] defines mathematical thinking as the explicit or vague application of mathematical techniques, concepts, and processes in the solving of problems. Keith [9] emphasized that mathematical thinking is a process that helps us better understand information about the world in which we live and maximizes our options.

The data, situations, and objects of mathematical thinking are the skills of being able to judge with mathematical logic. Mathematical thinking is a process work. When the inputs of this process are studied, there is the method of interpreting the person thinking, the problem, the data regarding the problem, and the data (thinking technique). However mathematical these inputs are, mathematical thinking is qualitative at that level [4]. According to Bukova, mathematical thinking is thought of as attaining new knowledge or concepts with abstraction, estimating, generalizing, establishing and testing hypotheses, thinking through, proving, and defining, using the mathematical knowledge and concepts that the individual had previously learned [10].

In the most general sense, mathematical thinking can be defined as "using mathematical techniques, concepts, and methods, directly or indirectly, in the problem-solving process" [11]. Individuals use mathematical thinking, with and without realizing it, in solving the events and phenomena they encounter at every stage of their lives. Therefore, it is a form of thinking that must be used in all fields today. All throughout life, individuals try to solve problems at work and at school [12]. There is a need for mathematical thinking for this. Therefore, it is necessary to develop the mathematical thinking of individuals to meet their needs in every field.

Considering the entirety of mathematical thinking, it was noticed that it was quite abstract. The researchers resorted to examining the matters that distinguished the characteristics and components of mathematical thinking and mathematical thinking from other types of thinking, for the purpose of "abstracting" mathematical thought. In this sense, mathematical thinking is set apart from other ways of thinking with its characteristics of attaining new knowledge or concepts by estimating, generalizing, conjecturing and testing, abstraction, reasoning, and proving [13]. On the other hand, when the literature is reviewed, it is seen that different researchers have tried to reveal the components of mathematical thinking. For example, Tall [14] stated that mathematical thinking covers components such as abstraction, synthesizing, generalizing, modelling, problem solving, and proof. Stacey, Burton, and Mason [15] examined the components of mathematical thinking: specializing, generalizing, conjecturing, justifying, and convincing. Hacısalihoğlu, Mirasyedioğlu, and Akpinar [16] stated that the process of mathematical thinking consisted of the components of detailing (specializing), generalizing, conjecturing, and convincing, based on the work of Stacey, Burton, and Mason. Liu [17] defined mathematical thinking as "the union of estimating, induction, deduction, sampling, generalizing, analogy, formal and informal reasoning, confirmation and similar complex processes". This study was conducted using the components obtained within the theoretical framework of Stacey, Burton, and Mason.

While abstracting mathematical thought, it is necessary to consider its characteristics, components, and other aspects that set it apart from other types of thinking. However, if it is considered that various mathematical techniques are used in the fields of mathematics such as arithmetic, algebra, geometry, and probability [18], the use of different fields of mathematics in the process of mathematics instruction could contribute to the development of students' mathematical thinking.

In this study, efforts were made to include the Graph Theory of mathematics, which is found abundantly in physics, chemistry, computer networks, economics, administrative science, data communication, transportation planning, engineering, and similar areas of daily life, into the mathematics instruction process. Graph Theory is a type of network structure formed from nodes (peaks) and the edges that connect these nodes to one another. This is directly related to the concept of mathematical modelling emphasized in the instruction program. Because mathematical modelling is the process of trying to mathematically express an incident, phenomenon, or relationship between events within or outside of mathematics, and of revealing patterns within events and phenomena [19]. With this perspective, the relationship between events or phenomena and the nodes of the graph can be thought of as the edges of the graph. The aim of the use of mathematical modelling within the instruction process is the perspective that "giving individuals the ability to solve problems in real life should be the main goal of mathematics education" $[20,21]$. Problem-solving is one of the concepts found in the focus on mathematical thinking in individuals. As'ari [22] vocalized this issue as if suitable problems are selected; the mathematical thinking skills of the students can be developed. When considering that problem solving plays a key role in mathematical thinking, it was emphasized in the relevant literature that the Graph Theory is suitable for problem solving, can provide adequate variety for students in an instructional 
environment, and is an excellent tool that can capture the attention of the students [23-25]. The fact that a scarcity of studies for the use in the high school mathematics instruction process of the Graph Theory was encountered in the literature evokes feelings of this study being a necessity. In this context, the problem sentence of the research is specified below:

\section{Research Question}

How are the mathematical thinking processes of the students in the instruction of the lower learning field of "Sequences", based on the Graph Theory?

\section{Limitations}

This study was limited to the 2018-2019 Academic school year, a public school found in Balıkesir, 12th -grade students, and the "12.2.1.3. Conducting operations using the properties of the arithmetic and geometric sequences" subject of the Real Number Sequences, the 12th -grade "Sequences" lower learning areas.

\section{Materials and Methods}

A fundamental, qualitative research approach was adopted in this study, in which the mathematical thinking processes of 12 th-grade students were examined. With this research approach, a qualitative process was attempted to be monitored to reveal the search to discover, understand, and interpret the perspectives and learning processes of the individuals included in the graph-theory-based instruction applications.

\subsection{Study Group}

A purposeful sampling method was chosen to be able to determine the working group for the research. With the typical case sampling method, the study was conducted by choosing a typical public secondary school (proximity to city average in terms of student placement in university, socio-economic level, teacher-student ratios, etc.) in central Balıkesir in this research, where the mathematical thinking processes of students was examined in instruction carried out based on the graph theory. Taking mathematics report card grades as a criterion in previous years, students with average and high levels of success were chosen. The reason for this is that it became the idea that rich data would be unable to be collected from students with low levels of success because mathematical thinking includes the characteristics of attaining new knowledge or concepts with estimation, generalizing, conjecturing and testing, abstraction, reasoning, and proving [26].
As a result, two girls and two boys with average and high mathematics success, who were in the 12th grade of a public school in Balıesir in the 2018-2019 Academic School year constituted the working group of the research.

\subsection{Data-Collection Tools}

The data in the study were collected with the two worksheets the researchers prepared, the clinical interviews held during the application, and through unstructured observations. Focus group interviews were conducted with a faculty member working in the Faculty of Arts and Sciences, a field education expert, and two teachers. In the interviews, learning areas thought to be suitable for Graph-Theory-supported learning were attempted to be specified, primarily in the secondary education mathematics curriculum. These are "Sets" in the 9th grade, "Numeration and Probability" in the 10th grade, "Functions" in the 11th grade, and "Sequences" in the 12th grade. The achievements of "12.2.1.3. Conducting operations using the properties of the arithmetic and geometric sequences", subject to the Real Numbers Sequence of the 12th-Grade Sequences lower learning areas were reported as a result in line with the views, particularly of the secondary education teachers. However, the relevant achievement includes two different concepts as arithmetic and geometric sequences. When the relevant textbooks are examined, it was determined that there were four properties belonging to arithmetic sequences and five properties belonging to geometric sequences. In line with expert opinions, worksheets were developed by focusing on the "central difference" and "central factor" that were emphasized in the definitions of arithmetic and geometric series, respectively.

Each worksheet was created upon the graphs; peak numbering and contained four questions thought to be able to assess the mathematical thinking processes of the students. The first questions were related to specializing, the second questions to generalizing, the third questions to conjecturing, and the fourth questions to proving, in accordance with the stages of mathematical thinking.

The validity and reliability of the worksheets was attempted to be ensured with the pilot study, with consideration of expert opinions. First, four prepared worksheets were arranged in line with the views of a faculty member who had done his or her master's and doctorate in the field of graph theory, they were presented to an expert in the field of mathematics and a teacher, and two worksheets were decided upon in line with the recommendations. The pilot study was carried out by administering the two given worksheets to three 12th-grade students of another school in central Balıkesir. As a result of the pilot study, no problems were encountered with regard to the understandability of the questions. One of the prepared worksheets is presented below: 


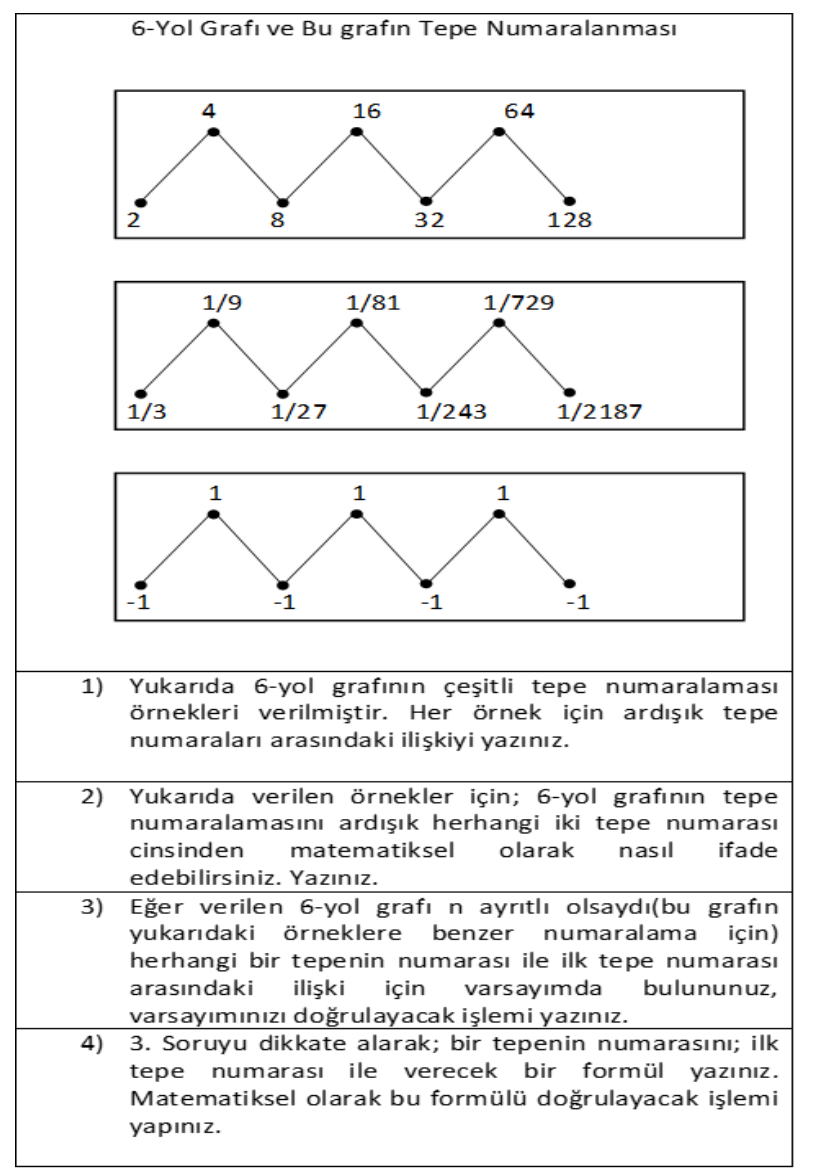

Figure 1. Worksheets 2

An eight-path graph was used in the questions in the worksheet above. The questions on the second worksheet were asked over a six-path graph. For the specializing and generalizing stages, the various peak numberings of a six-path graph were provided and questions similar to questions 1 and 2 of the worksheet above were asked. With regard to the conjecturing stage, the students were asked to conjecture for a formula that would provide any peak number from the type of the first peak number. And in question 4 , write and prove a formula for their conjecture in the previous question, in order for an n-edge path graph to similarly number the relationship in the second question.

\subsection{Data Collection}

Clinical interviews were conducted with the students in this study, which aimed to study the mathematical thinking processes of students in the instruction process of the graph-theory-supported topic of "Sequences". In the interviews, the students were asked to interpret the problems, think out loud, and write the solutions in detail; the researcher also directed questions to the students that would reveal their thinking processes. The clinical studies were conducted in one or two sessions for each student.

\subsection{Data Analysis}

Qualitative analyses were used for the data acquired from the worksheets. An answer key that included possible answers previously expected was prepared. While preparing the answer key, the 12th-grade mathematics textbook was utilized. Later, the written responses that the students gave to each question were examined in detail. Each of the students' answers was coded individually for all the questions in the two worksheets with consideration of the hypothetical framework. The answers were arranged based on the similarities, and wider categories were attained. A field expert examined all the student responses in terms of the reliability of the coding, the researcher reexamined them, and they reached an agreement with regard to the coding. For the external validity of the research, direct quotations were taken from the foundational characteristics of the qualitative analysis and the data were interpreted in detail.

\section{Findings}

\subsection{Specializing}

Specializing means to choose clear or systematic examples and to examine these examples over a problem in order to understand and interpret the status of a problem. In the most basic sense, special circumstances can be expressed as searches, looking at the various examples. In this stage, the completion, demonstration, explanation, and choosing one or more examples is relevant [27]. The first questions on the worksheets (W1Q1 and W2Q1) were in the form of "...write down the relationship between sequential peak numbers" for the various peak numbers of the eight-path and six-path graphs, respectively, and were related to studying and defining the examples. The behaviors in this stage are gathered under code 2 . These are correctly knowing and incorrect/ leaving blank for the specially requested situations. Sample student responses are given in the table below.

Table 1. Sample student responses provided in the specializing process

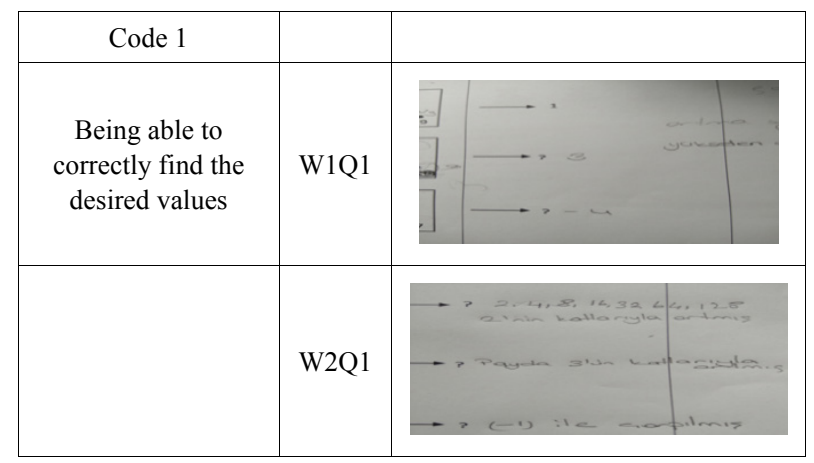

The specializing process begins with students understanding the problem they face. For the first questions of the worksheets, the students carefully examined all the given examples. "...the peak numbers rose 3 by $3 . . . "$ (S1), and "...a peak number was twice as large as one previous..." (S4) can be given as examples from the interviews. When 
the responses were examined and based on observations, all students were able to accurately find the values asked to be determined without difficulty.

\subsection{Generalizing}

Generalizing is estimating about wider situations by acting on a few examples. Or being able to be expressed as a pattern/ relationship search. Setting out from a certain number of operations, a decision is attempted to be made about the claim, showing the specializing operation is performed during generalizing [27]. Some strategies the students may use in this process could be considered as creating examples, organizing examples, and more for the determination of relationships, collecting as many samples as possible, and testing conjectures [28]. The first questions on the worksheets (W1Q2 and W2Q2) were in the form of “...how can you mathematically express any two sequential peak numbers from their type" for the various peak numbers of the eight-path and six-path graphs, respectively, and were related to acquiring a general rule, mostly by expanding observations. The student responses at this stage are gathered under code 3 . These are the correct linguistic/ mathematical expression of the relationship, the incorrect linguistic/ mathematical expression of the relationship, and leaving a blank. Sample student responses are given in the table below.

Table 2. Sample student responses provided in the generalizing process

\begin{tabular}{|c|c|c|}
\hline Code 1 & & \\
\hline & W1Q2 & $\begin{array}{l}\text { 2. Drrete tein }+3 \\
\text { 3. Dret iem }-4\end{array}$ \\
\hline \multirow[t]{2}{*}{$\begin{array}{l}\text { Linguistically/mat } \\
\text { hematically stating } \\
\text { the relationship } \\
\text { correctly }\end{array}$} & W1Q2 & $\begin{array}{l}V_{n}+1=V_{(n+1)} \\
V_{n}+3=V_{(n+1)} \\
V_{n}-4=V_{(n+1)}\end{array}$ \\
\hline & W2Q2 & 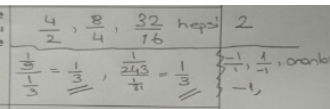 \\
\hline
\end{tabular}

When examining the student responses, it can be said that all the students provided correct responses at this stage. Three of the students were able to express the relationship in the second question both linguistically and mathematically on both worksheets accurately. However, one student was unable to write the relevant question mathematically on the second worksheet despite writing it linguistically. With regard to this, when the question "Can you write it mathematically?" was asked in the interview, they gave the response of "...the forces of 2, the forces of $1 / 3$, and the forces of -1 , and the proportion of the two sequential peak numbers to one another is stable." This situation was interpreted as the student knew the response but didn't want to write it at that moment.

While examining the responses S2 gave to W1S2 in the student responses above, the interview conducted with the student are provided below:

I: While solving the problem, why did you choose an orthography in the form of $\mathrm{v}_{\mathrm{n}}$ and $\mathrm{v}_{(\mathrm{n}+1)}$ rather than using a demonstration such as $\mathrm{v}_{1}, \mathrm{v}_{8}$ to show the peaks on the eight-path graph.

S1: Any of the peaks is a certain number greater or lesser than the previous one. I used $n$ to show any of the peaks in the graph because I knew somehow that there were 8 edges.

\section{I: Was what you wrote only for the eight-path graph?}

S2: (After a brief pause) No, if I write it like this, it would work for all of them -for all the graphs, I mean... But what I wrote isn't wrong

Another interesting point in this response was that the student used parentheses in the $\mathrm{v}_{(\mathrm{n}+1)}$ index to show any of the peaks. The student's preference was notable while the fundamental terms, symbols, and demonstrations for graph theory were explained to the students, despite no such demonstration having been done. In the interview conducted with the student on this topic:

\section{I: So, can you explain why you took the $n+1$ index into the parentheses?}

S2: I am careless when doing operations with parentheses on other mathematics topics. I didn't want to make a mistake here.

\section{I: What do you mean when you say careless?}

S2: I don't put parentheses when I say to myself "Let's solve the problem real fast" on exams. I found the wrong result. I thought that if I don't take it into the parentheses here, it would be wrong.

Considering the anxieties of the students on the topic of operations with parentheses, it was decided that there would be intervention on this issue.

\subsection{Conjecturing}

Conjecturing emerges in the processes of specializing and generalizing and is a process of researching the accuracy of a thesis by estimating that it may be true. Actions such as making linguistic or mathematical estimates, formulating mathematical claims, producing results from theses, and establishing and testing hypotheses could be relevant in this process [27]. By examining a sufficient number of examples, relationships and patterns were discovered, and a judgment was reached, setting out from the discovered patterns [28]. The third question on the first work sheet was stated as "...make a conjecture for a formula that would provide any peak number from the sequential type of peaks, if the given path graph had been n-edged..." The third question on the second worksheet was stated as "...make a conjecture for the relationship 
between any of the peak numbers and the first peak number, if the given path graph had been n-edged. The student responses at this stage are gathered under code 3 . These are in the form of linguistic conjecturing, mathematical conjecturing, and leaving blank. One of the students left the third question on the second worksheet blank. Sample student responses are given in the tables below.

Table 3. Sample student response provided in the linguistic conjecturing process

\begin{tabular}{|c|l|l|}
\hline Code 1 & & \\
\hline $\begin{array}{c}\text { Linguistically } \\
\text { conjecturing }\end{array}$ & W2Q3 & $\begin{array}{l}\text { Ortak kat kador } \\
\text { artiyorsa; kacinci tepe } \\
\text { ise ilk tepe ile o kodor } \\
\text { kat garpilir. } \\
\text { Denerim. 4.tepe } \frac{1}{3}-\left(\frac{1}{3}\right)^{3}\end{array}$ \\
\hline
\end{tabular}

In the first worksheet, all the students chose to make mathematical conjectures rather than linguistic conjectures. In the second worksheet, however, two students chose to make linguistic conjectures. The dialog during the interview with the student who gave the response in the table is provided below:

I: Can you explain what you wrote, "up to that multiple"?

S3: In all the examples, it was growing with a multiple of a shared number. I multiplied it with that.

I: But in the example you gave, it looks like there's a missing multiple. How can you explain the difference that forms between the number of peaks you chose and the exponent of the multiple?

S3: For example, because the first peak number is 1/3, I took that as the factor. When counting the next ones, a difference arose between the peak and the exponent, and I noticed that.

\section{I: So, can you tell me this for the other examples?}

S3 I tried in all of them, it works.

Table 4. Sample student responses provided in the mathematical conjecturing process

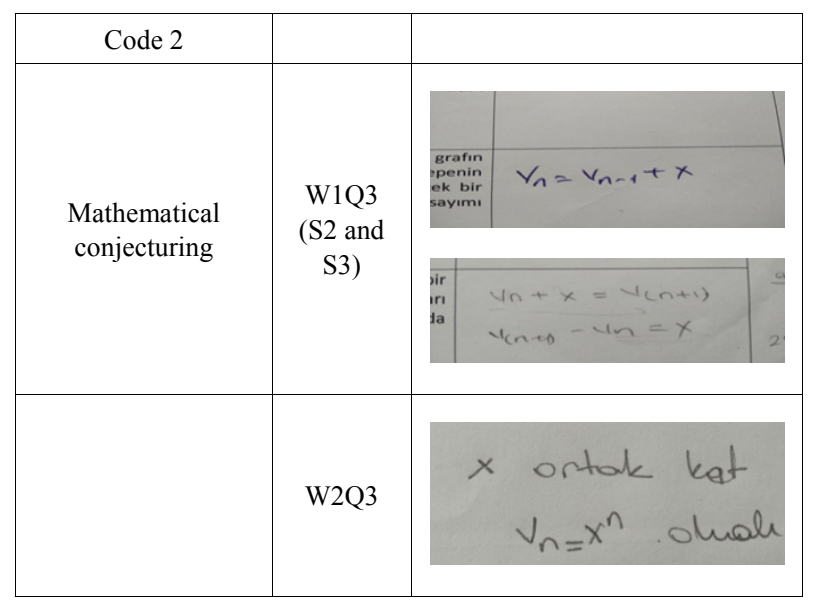

All of the students chose to make mathematical conjectures for the third question on the first worksheet. The reasons for this could originate from the question, which was prepared based on the expression of "...the difference between the sequential terms is equal to the same fixed number..." found in the definition of the arithmetic sequences, including simple arithmetic operations. The fact that the students were encountering algebraic expressions as of the 6th grade could have given rise to the necessity to respond to this question mathematically. However, when the responses above given to $\mathrm{W} 1 \mathrm{Q} 3$ are compared, it can be said that $\mathrm{S} 3$ overlooked the information that an n-edge graph $(\mathrm{n}+1)$ had a peak and that this was consistent with the concept of arithmetic sequences given in the textbooks.

When examining the response of the student given on W2Q3, it is understood that the student discovered the connections between the examples by examining enough examples and made a judgment, setting out from the discovered patterns.

\subsection{Making Proofs}

Proof, an important concept in learning mathematics [30], is also important for mathematical thinking. While making proofs, actions such as explaining a hypothesis, saying why it is true or false, and choosing and using different logical ways of thinking (inductive and deductive thinking) and varieties of proof become relevant. The fourth questions on the worksheet were expressed in the form of "...write a formula to give a peak number from the first type of peak number. Perform the operation that will mathematically verify this formula." The student responses at this stage are gathered under code 3 . These are specified as arithmetic proof, algebraic proof, and questions left incomplete/incorrect/blank. Three of the students were able to answer W1Q4 at this stage, and one student left the question blank. Two of the responses were arithmetic proofs, while 1 of the responses was an algebraic proof. While two students were able to answer W2Q4, one student left it incomplete and another student left it blank. Sample student responses are given in the tables below.

Table 5. Sample student responses of arithmetic proof given in the proof process

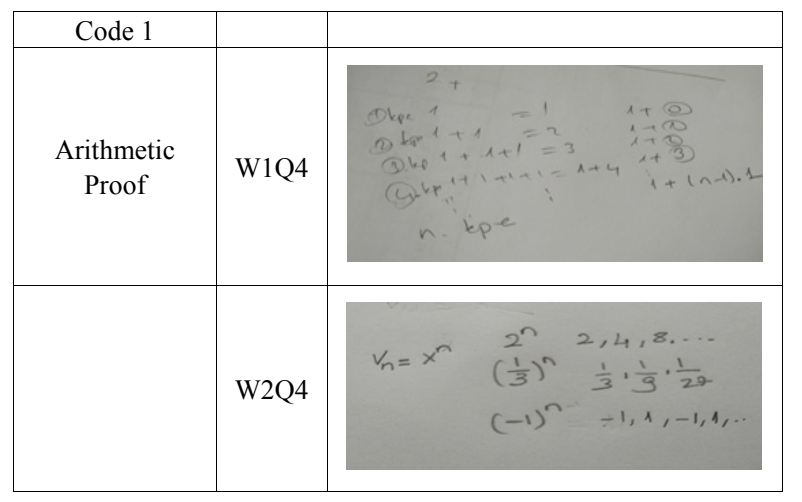

When examining the answers to the fourth question on 
the first worksheet, it can be said that S1 made proofs in a similar manner in the path graphs given in the second and third examples. The student was able to reach the formula of " $\mathrm{a}_{\mathrm{n}}=\mathrm{a}_{1}+(\mathrm{n}-1) \mathrm{d}$ " by working on the examples. When the student was asked whether this situation could materialize in other path graphs, he/she was able to show that it did by providing various examples. This situation was interpreted as the students being able to achieve a generalization of $a_{n}=a_{1}+(n-1) d$ using numerical approaches. A similar situation is valid within the student response given to W2Q4 in Table 5.

Table 6. Sample student responses of algebraic proof given in the proof process

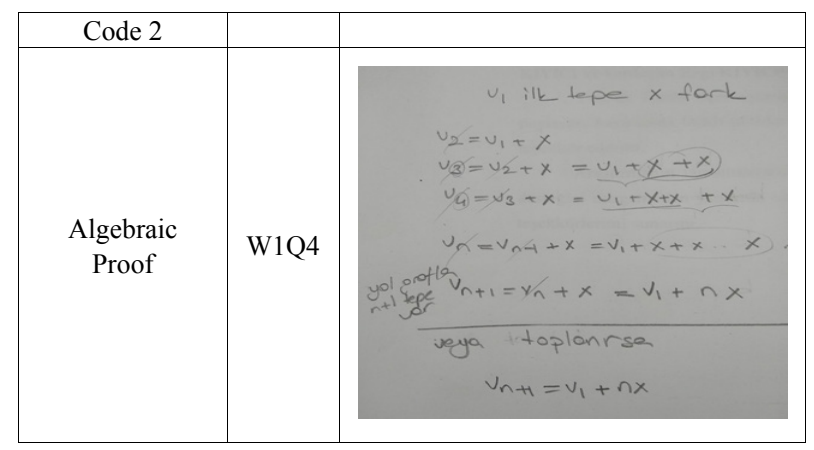

The continuation of Table 6

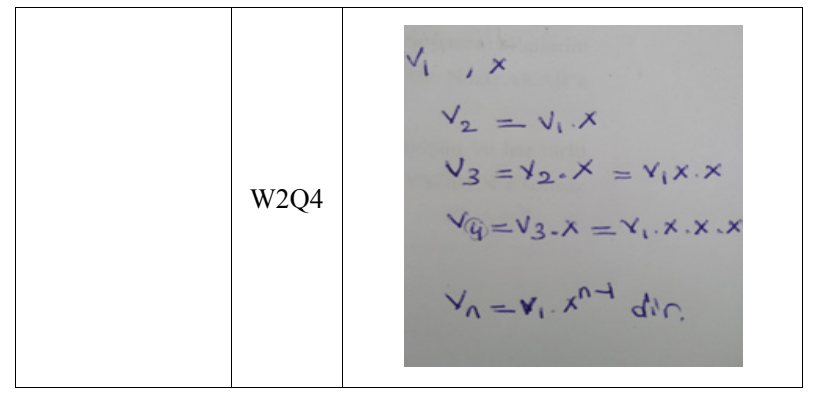

When examining Table 6, it was decided that the responses the students gave to the algebraic proof were consistent with the 12th-grade text book being studied and that, for this reason, the proofs could be accepted. When the students were asked why the chose the proof in this manner, they replied "....no matter how many edges the path graph had, I thought doing it like this would be useful...(S1)," and "...I did it like this. Moreover, it was useful in all the given examples...(S3)." These responses show that the students prefer deductive thinking in the proof stage.

After administering the worksheets, the students were asked a few of the examples from the relevant topic in the textbooks, and they were asked to provide solutions. They were asked to compare the worksheets and textbook examples after their solutions. Some of the student responses are presented below:

"...the final examples were asked more linguistically. Whereas we used the "paths" in the worksheets, it was easier to deal with the numbers over the peaks..." "...for example, while solving the problem 'if the 2, a, b, c, 50 finite sequences is an arithmetic sequence, find the total of $a+b+c$ ', I thought of the path graph, placed the numbers at their peaks, and solved the problem like that..."

"...working with shapes rather than what's in the text book was both more interesting and easier..."

\section{Conclusions}

The acquired results are attempted to be summarily presented in the table below in this study, which aimed to study the mathematical thinking processes of students in the instruction process of the graph-theory-supported topic of "Sequences".

Table 7. Student responses to the questions in the worksheets

\begin{tabular}{|c|l|l|}
\hline $\begin{array}{c}\text { Question } \\
1\end{array}$ & \multicolumn{1}{|c|}{ W1 } & \multicolumn{1}{c|}{ W2 } \\
\hline $\begin{array}{c}\text { Question } \\
2\end{array}$ & $\begin{array}{l}\text { 4 linguistic relationships } \\
4 \text { mathematical } \\
\text { relationships }\end{array}$ & $\begin{array}{l}4 \text { linguistic relationships } \\
4 \text { mathematical } \\
\text { relationships }\end{array}$ \\
\hline $\begin{array}{c}\text { Question } \\
3\end{array}$ & 4 mathematical conjectures & $\begin{array}{l}2 \text { linguistic conjectures } \\
1 \text { mathematical conjecture } \\
1 \text { blank }\end{array}$ \\
\hline $\begin{array}{c}\text { Question } \\
4\end{array}$ & $\begin{array}{l}\text { 2 arithmetic proofs } \\
1 \text { algebraic proof } \\
1 \text { blank }\end{array}$ & $\begin{array}{l}2 \text { arithmetic proofs } \\
1 \text { missing } \\
1 \text { blank }\end{array}$ \\
\hline
\end{tabular}

In the first questions related to specializing in the worksheets, the students were able to perform the tasks regarding examining and defining the examples without difficulty. Köse and Yıldırım [31], Keskin, Akbaba, and Altun [32], and Arslan and Y1ldiz [27] obtained similar results in their studies, and the students were able to easily fulfill the specializing process.

In the generalizing process, students were able to express linguistically as well as mathematically the generalizations they reached. It is known that students were able to linguistically write the relationship in the generalizing processes of the problems but had difficulty writing them algebraically [27,31-34]. However, it was observed that the students in this study were able to easily fulfill both situations. It is thought that the reason for this that the path graphs in the questions help the students make abstractions as a visual model and also reveal the relationship between the variables.

In the conjecturing stage, a total of 8 responses that 4 students who participated in the study provided to 2 questions, and the conclusion was reached that 7 were correct and 1 was left blank. When considering that a blank response was related to the subject of the geometric sequence, it was observed that deficiencies occurred that originated from the knowledge of the student relating to exponential numbers and that, for this reason, the student chose not to respond. Another notable situation in this section is that the students chose more often to make 
mathematical conjectures. Additionally, another notable situation was that the success of the students in the conjecturing stage dropped after the specializing and generalizing stages.

When moving to the proof stage, the conclusion was reached that the students preferred arithmetic proofs. Of the five correct answers given in this stage, only one was an algebraic proof. The change of the mathematics curriculum in Secondary education institutions in our country could be shown to be the reason for this situation. Such that the students in the working group were unable to process the topic together with the subject of "Proof Methods", which they will see in the 11th grade, being taken into the 9th grade. This situation led to the students having knowledge gaps, and they tried to solve the final problem on the worksheets based on their prior knowledge. The one student who performed an algebraic proof was the student who was in the successful group and who stated that he/she had special interest in mathematics.

Generally, when previous research is examined, it can be said that success of students falls when mathematical thinking moves up to the upper stages [27,35-36]. In this study, although the drop in success had begun in the third stage of mathematical thinking, conjecturing, only 1 of the 8 responses given was blank, and no incorrect or incomplete responses were encountered. It is thought that the reasons for this are the $(\mathrm{a}, \mathrm{d})$-inverse magic numbers for the path graphs of the graph theory taken into the scope of the research. The results of this study show that, in the process of mathematics teaching, especially if teachers provide enough diversity students by using different fields of mathematics, they can increase the performances of students in mathematical thinking stages. However, in order for the effects of this situation to be determined, researchers are recommended to conduct experimental studies. It could also originate from the failure to present activities that pull the mathematical thinking of the students in the educational institutions up to the highest levels. With reference to this and based on the results obtained in this research, it is recommended that more importance be given in schools to stages of mathematical thinking such as conjecturing and that, especially in these stages, graph theory concepts and structures be utilized rather than text books.

\section{REFERENCES}

[1] Ş. Gözen. Mathematics and Teaching, Evolution Science Series: 18, İstanbul, 2001.

[2] E. Ersoy, N. Başer. The Development of Mathematical Thinking Scale, Cilt: 21, No:4 (Special İssue) Kastamonu Education Journal, 1471-1486, 2013.

[3] Ministry of National Education (MoNE). The Secondary
Mathematics Curriculum (9, 10,11 and 12. Classes), 2018.

[4] C. Yıldırım. Mathematical Thinking. İstanbul: Remzi Bookstore, 2004.

[5] E. Ersoy. High-level Cognitive Thinking Skills and the Changes in Affection Acquisitions in the Problem-Based Learning Process. PhD Thesis. Dokuz Eylul University Institute of Educational Science, İzmir, 2012.

[6] A. Umay. Mathematical Reasoning Ability. Hacettepe University Education Faculty Journal, 24, 234-243, 2003.

[7] A. H. Schoenfeld. Learning to Think Mathematically: problem solving, metacognition, and sense-making in mathematics. (Ed. D.A. Grouws). Handbook of research on mathematics teaching and learning: a project of the national council of teachers of mathematics. (pp.334-370). New York: Macmillan, 1992.

[8] P. B. Henderson. Materials Development in support of Mathematical Thinking, 2002.

http://blue.butler.edu/phenders/iticse2002WG.rtf, Access: $15 / 12 / 2017$.

[9] D. Keith. Finding your inner mathematician. Chronicle Of Higher Education. 47(5), 5-6, 2000.

[10] E. Bukova. The development of new curriculum to overcome the students' difficulties in perceiving the concept of limit and constructing the relationship between the concept of limit and the other mathematical concepts. Unpublished Doctoral Dissertation, Dokuz Eylul University Institute of Educational Science, İzmir, 2006.

[11] P. B. Henderson, B. Marion, S. J. Fritz, C. Riedesel, J. Hamer, C. Scharf, et al. Materials development in support of mathematical thinking, 2002. http://www.cs.geneseo. edu/ baldwin/math-thinking/iticse2002-paper.pdf. Acsess: 30.04.2018.

[12] R. Blitzer. Thinking Mathematically. Upper Saddle River, NJ: Prentice Hall, 2003.

[13] H. Alkan ve E. Bukova Güzel. Development of Mathematical Thinking in the Student Teachers. Gazi Education Faculty Journal, 25(3), 221-236, 2005.

[14] D. Tall. Advanced Mathematical Thinking. USA: Kluwer Academic Publishers, 2002.

[15] K. Stacey, L. Burton \& J. Mason. Thinking Mathematically, England: Addison-Wesley Publishers, 1985.

[16] H. Hacısalihoğlu, Ş. Mirasyedioğlu \& A. Akpınar. Mathematics Education: Constructivist Teaching and Learning in Mathematics. Ankara: Asil, 2003.

[17] P. H. Liu. Do teachers need to incorporate the history of mathematics in their teaching? The Mathematics Teacher, 96(6), 416-421, 2003.

[18] J. Dindyal. Algebraic Thinking in Geometry at High School Level. Unpublished Doctoral Dissertations, Illinois State University, 2003.

[19] L. Verschaffel, B. Greer \& E. De Corte. Everyday knowledge and mathematical modeling of school word problems. In K. P. Gravemeijer, R. Lehrer,H. J. van Oers, \& L. Verschaffel (Eds.), Symbolizing, modeling and tool use in mathematics education (pp. 171-195). Dordrecht, 
The Netherlands: Kluwer Academic Publishers.

[20] K. Gravemeijer \& M. Stephan. Emergent models as an instructional design heuristic. In Gravemeijer, K., Lehrer, R., Oers, B. \& Verschaffel, L. (Eds.).Symbolizing, Modeling and Tool Use in Mathematics Education, 145-169, Kluwer Academic Publishers, Netherland, 2000.

[21] R.A. Lesh \& H. Doerr. Foundations of model and modeling perspectives on mathematic teaching and learning. In R.A. Lesh and H. Doerr (Eds.), Beyond Constructivism: A models and modeling perspectives on mathematics teaching, learning, and problem solving. Mahwah, NJ: Lawrence Erlbaum, 2003.

[22] A.R. As'ari. Optimizing Problem Solving Activity for Teaching Mathematical Thinking, UNISMA, International Seminar on Mathematics Education and Graph Theory, Islamic University of Malang, 3-9, 2014.

[23] N. Asghari, A. Shahvarani \& A. R. Haghighi. Graph Theory as a Tool for teaching Mathematical Processes, International Journal for Cross-Disciplinary Subjects in Education (IJCDSE), Volume 3, Issue 2, 2012.

[24] M. Buhler. Spock, Euler and Madison: Graph Theory in the Classroom, Undergraduate Honors Theses, Utah State University, 2013.

[25] S.M Uyangör \& D. Üzel. The Place of Graph Theory in Teaching with Using Concept Maps, Gazi University, Gazi Education Faculty Journal, Volume 25, Issue 2, 135-144, 2005.

[26] A. Y1ldırım, \& H. Şimşek. Qualitative Research Methods in the Social Sciences. Ankara: Seçkin Publishing, 2013.

[27] S. Arslan, \& C. Y1ldiz. Reflections from the Experiences of 11th Graders during the Stages of Mathematical Thinking, Education and Science, 35(156), 17-31, 2010.

[28] P. Pilten. The Effect of Metacognitive Instruction on Mathematical Reasoning of fifth grade primary school students. Unpublished Doctoral Dissertations. Ankara: Gazi University, Institute of Educational Sciences, 2008.

[29] L. Burton. Mathematical Thinking: The Strugglef Or Meaning. Journal of Researching Mathematics Education, Vol. 15(1), 35-49. 1984.

[30] E. J. Knuth. Proof as a tool for learning mathematics. Mathematics Teacher, 95(7), 486-490, 2002.

[31] D. Yıldırım \& N. Yavuzsoy Köse. Mathematical Thinking Processes of Secondary School Students in Polygon Problems. Abant İzzet Baysal University, Education Faculty Journal, 18 (1), 605-633, 2018.

[32] M. Keskin, S. Akbaba \& M. Altun. Comparison of $8^{\text {th }}$ and $11^{\text {th }}$ grade Students Behaviours at Mathematical Thinking. Journal of Educational Sciences, 1, 33-50, 2013.

[33] F. Rivera \&, J. R. Becker. Accounting for Sixth Graders' Generalization Strategies in Algebra. In S. Alatorre, J. Cortina, M. Sáiz, \& A. Méndez (Eds.), Proceedings of the 28th Annual Meeting of the North American Chapter of the International Group for the Psychology of Mathematics Education, Vol 2, pp.155-157, Mérida, México: Universidad Pedagógica Nacional, 2006.

[34] M. F. Özmantar, E. Bingölbali \& H. Akkoç. Mathematical
Misconceptions and Solutions. Ankara: Pegem Publishing, 2008.

[35] S. Moralı, I. Uğurel, E. Türnüklü ve S. Yeşildere. The Views of the Mathematics Teachers on Proving. Kastamonu Education Journal, 14(1), 147-160, 2006.

[36] Ö. Özer \& A. Arıkan. The Level of Proving of student in High School Math Classes. UFBMEK V, Middle East Technical University, Ankara, 2002. 